\title{
Assessing the Effects of Alcohol Consumption on the Work Performance of Teachers in the Builsa North District of the Upper East Region of Ghana
}

\author{
Akum-Yeri Whittaker Ayom-Bil Robert ${ }^{1}$, Der Muonir Edmund, * \\ ${ }^{1}$ Tamale Teaching Hospital, Blood Bank, Tamale, Ghana \\ ${ }^{2}$ Department of Pathology, School of Medicine and Heath Sciences, University for Development Studies and the Tamale Teaching Hospital, \\ Tamale, Ghana
}

Email address:

maadelle@yahoo.com (D. M. Edmund)

${ }^{*}$ Corresponding author

\section{To cite this article:}

Akum-Yeri Whittaker Ayom-Bil Robert, Der Muonir Edmund. Assessing the Effects of Alcohol Consumption on the Work Performance of Teachers in the Builsa North District of the Upper East Region of Ghana. Central African Journal of Public Health.

Vol. 6, No. 1, 2020, pp. 48-54. doi: 10.11648/j.cajph.20200601.18

Received: December 7, 2019; Accepted: December 19, 2019; Published: February 10, 2020

\begin{abstract}
Background: Alcohol consumption by teachers may impede or reduce productivity and cause lost for employers. The aim of the study was to ascertain the alcohol consumption patterns of teachers in the Builsa north district and the effects on work performance. Material and methods: This was a cross-sectional descriptive study. Data were analysed using SPSS software (version 21.0). Associations determined using Fisher's exact test. Results: Ninety-nine

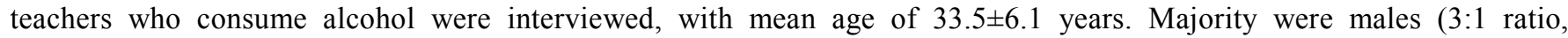
$\mathrm{p}<0.0005)$. The great majority $(83.8 \%, \mathrm{P}<0.0001)$ were trained; with $(66.7 \%)$ being University graduates. Approximately $99.0 \%(\mathrm{P}<0.0001)$ had friends who drink alcohol, and $86(86.9 \%)$ drink alcohol with their friends. Alcohol intake was found to affect a person's social life $(91.9 \%)$, family obligations, $(97.0 \%)$ and finances $(93.9 \%)$. Approximately $86.9 \%(\mathrm{P}<0.0001)$ agreed alcohol intake is a problem among teachers. Many (63.6\%) of the teachers take in alcohol every day, and approximately $80.8 \%$ have been drinking over one year. About $23.2 \%$ drink anytime during the day, while $33.0 \%$ spending one or hours in a spot. The reasons for alcohol intake among teachers were: socialisation (46.5\%), relaxation (31.3\%) and to forget problems $(21.2 \%)$. The negative effects of alcohol intake on productivity were; hangover whiles at work (73.7\%), absenteeism (88.9\%), missing lessons in school due to time spent at spots $(84.9 \%)$ and inability to complete syllabus (74.7\%). Conclusion: The study concluded that teachers' alcohol consumption affects their work performance greatly in the Builsa North District.
\end{abstract}

Keywords: Teacher, Alcohol Consumption, Work Performance, Builsa North District, UER-Ghana

\section{Introduction}

Prior to the modern era, alcoholic beverages were known in all tribes, societies and villages all over the world except in Australia, Oceania and North America [1]. Globally, alcohol is used for different reasons and purposes and it usage is often associated with many social activities across the world [2-4].

In Europe and other parts of the world, alcohol is used in marriage and naming ceremonies, dinner and banquet parties. In Africa alcohol is used in offering sacrifices and rituals to smaller gods and in social activities like marriages, naming ceremonies and funeral grounds. Still in Africa, alcohol is used during communal activities like farming, constructing of houses/buildings and any other activity that is undertaken communally. Thus, alcohol consumption have generally become an accepted social habit in many countries of the world and more so in some developing countries, where the revenue earned from trading in alcohol constitutes a large percentage of the national income $[4,5]$. In Ghana, like most parts of Africa, there are wide ranges of activities that involve the usage of alcohol. Similar conditions and activities 
can are found in the Builsa North District (BND) [6], these thus create fertile ground for increased alcohol consumption by individuals living in the area. The aim of this study was to ascertain whether teachers alcohol consumption affect their work performance in the Builsa North district of the Upper East Region of Ghana.

\section{Methodology}

\subsection{Study Area}

The Builsa North district (BND) is one of the thirteen (13) administrative districts in the Upper East Region of Ghana. It was curved out on $15^{\text {th }}$ March, 2012 by an Act of Parliament, 1993 (Act 462) with Sandema as its administrative capital from the then Builsa District created in 1974 under the Supreme Military Council One (SMC1) (Ghana Statistical Service, 2014) [3]. The BND consists of five major towns namely; Sandema, Chuchuliga, Seineisi, Weiga and Kaadema.

\subsubsection{Study Design}

This was a cross-sectional descriptive study.

\subsubsection{Study Population}

All teachers in the district.

\subsubsection{Sample Size Estimation}

We used the Yamane (1967:886).

$\mathrm{n}=\frac{\mathrm{N}}{1+\mathrm{N}(\mathrm{e})^{2}}$; where $\mathrm{n}=$ sample size, $\mathrm{N}=$ population size and $\mathrm{e}=$ level of precision and this formula was applied in this study using an assumption of $95 \%$ confidence level and 5\% level of precision.

By using the above formula to calculate the initial sample size (284), below is how the calculation was done.

$\mathrm{n}=\frac{\mathrm{N}}{1+\mathrm{N}(\mathrm{e})^{2}}$ but $\mathrm{N}=975$ and $\mathrm{e}=0.05$.

By putting the values into the formula,

$\mathrm{n}=\frac{975}{1+975(0.05)^{2}}=\frac{975}{3.4375}=284$ (to nearest whole number).

Therefore, $\mathrm{n}=284$ and which was the initial sample size.

After having gone through the above calculation to determine the initial sample size of 284 , there was a need to determine a sample fraction (SF) and so it was calculated and below shows how it was calculated.

Sample fraction $(\mathrm{SF})=\frac{n}{N}$; where $\mathrm{n}=$ sample size $=284$ and $\mathrm{N}=$ population size $=975$. By applying this formula $\left(\mathrm{SF}=\frac{\mathrm{n}}{\mathrm{N}}\right)$; it means $\mathrm{SF}=\frac{284}{975}=0.2913$ (to 4 decimal places). Hence, the sample fraction gotten was 0.2913 meaning $\mathrm{SF}=0.2913$.

There after the respondents were then put into the following strata below.

1. Primary school teachers $=353$.

2. Junior high school (JHS) teachers $=252$.

3. Senior high school (SHS) teachers $=370$.

Each stratum was then used to multiply by the sample fraction which is 0.2913 and the results gotten were then sum up.
Thus, primary school teachers $=353 \times 0.2913=103$ (to the nearest whole number),

JHS teachers $=252 \times 0.2913=73$ (to the nearest whole number) and

SHS teachers $=370 \times 0.2913=108$ (to the nearest whole number).

This implies that,

$$
\begin{gathered}
\text { Sample size }=\text { primary teachers }+ \text { JHS teachers }+ \text { SHS } \\
\text { teachers }=103+73+108=284 .
\end{gathered}
$$

Hence the initial sample size of 284.

Questionnaires were then issued to 284 respondents and they responded to it. After this number responded to the questionnaires, a total number of 99 questionnaires were then sieved out and used for the study as those respondents who responded to these particular questionnaires have indicated that they consume alcohol. Therefore, the actual sample size that has been used for this study was 99 respondents.

\subsubsection{Data Collection Tools}

A structured questionnaire was used to collect the data. The questionnaires were issued to the respondents and they answered them.

\subsubsection{Data Entry and Analysis}

Data was collected daily from respondents: sociodemographic variables, alcohol drinking pattern, and effects of alcohol drinking on the work performance of the teachers in the BND. It entered into the Statistical Package for Social Sciences (SPSS) version 21.0, and analysed. Frequency distributions and descriptive statistics were calculated for the variables. Associations determined using Fisher's exact test.

\subsection{Inclusion Criteria}

All teachers within the district who were actively teaching for a minimum of three months at the time of the research were included.

\subsection{Exclusion Criteria}

All teachers in administration positions at the district education office were excluded.

\section{Results}

Socio-demographic Characteristics of Respondents

A total of $99(34.9 \%)$ out of the 284 teachers interviewed consumed alcohol. Their ages ranged from 20-55 years, with a mean age of $33.5 \pm 6.1$ and a median age of 33.0 years respectively. The modal age group was 29-37 years. Many of the respondents were males $[(75.8 \%) \mathrm{p}<0.0001]$, with a male to female ratio of $3: 1$. The great majority of the respondents were professionally trained teachers $(83.8 \%$; $<<0.0001)$. Approximately, 70.7\%) were Builsas' by tribe (Table 1). 
Akum-Yeri Whittaker Ayom-Bil Robert and Der Muonir Edmund: Assessing the Effects of Alcohol Consumption on the Work Performance of Teachers in the Builsa North District of the Upper East Region of Ghana

Table 1. Socio-demographic characteristics of the respondents.

\begin{tabular}{|c|c|c|c|c|}
\hline Variable & & Frequency & Percentage & P-value \\
\hline \multirow{4}{*}{ Age } & $20-28$ & 29 & 29.3 & \multirow{7}{*}{$\mathrm{P}<0.0001$} \\
\hline & $29-37$ & 55 & 55.6 & \\
\hline & $38-46$ & 13 & 13.1 & \\
\hline & $47-55$ & 2 & 2.0 & \\
\hline Total & & 99 & 100 & \\
\hline \multirow{2}{*}{ Sex } & Male & 75 & 75.8 & \\
\hline & Female & 24 & 24.2 & \\
\hline \multirow[t]{2}{*}{ Total } & & 99 & 100 & \multirow{5}{*}{$\mathrm{P}<0.0001$} \\
\hline & Married & 64 & 64.6 & \\
\hline \multirow[t]{2}{*}{ Marital status } & Never married & 27 & 27.3 & \\
\hline & Separated & 8 & 8.1 & \\
\hline \multirow[t]{2}{*}{ Total } & & 99 & 100 & \\
\hline & Builsa & 70 & 70.7 & \multirow{4}{*}{$\mathrm{P}<0.0001$} \\
\hline \multirow{3}{*}{ Tribe } & Kasena-Nankana & 7 & 7.1 & \\
\hline & Frafra & 9 & 9.1 & \\
\hline & Others & 13 & 13.1 & \\
\hline \multirow[t]{2}{*}{ Total } & & 99 & 100 & \multirow{5}{*}{$\mathrm{P}<0.0001$} \\
\hline & Christianity & 87 & 87.9 & \\
\hline \multirow[t]{2}{*}{ Religion } & Islam & 3 & 3.0 & \\
\hline & Traditionalist & 9 & 9.1 & \\
\hline Total & & 99 & 100 & \\
\hline \multirow{3}{*}{$\begin{array}{l}\text { Educational } \\
\text { Level }\end{array}$} & SHS & 4 & 4.0 & \multirow{3}{*}{$\mathrm{P}=0.0022$} \\
\hline & College & 29 & 29.3 & \\
\hline & University & 66 & 66.7 & \\
\hline Total & & 99 & 100 & \multirow{4}{*}{$\mathrm{P}<0.0001$} \\
\hline Tyne of teacher & Trained & 16 & 16.2 & \\
\hline Іуре of teacher & Untrained & 83 & 83.8 & \\
\hline Total & & 99 & 100 & \\
\hline \multirow{3}{*}{ School one teaches } & Primary & 31 & 31.3 & \multirow{3}{*}{$\mathrm{P}<0.0001$} \\
\hline & Junior high & 32 & 32.3 & \\
\hline & Senior high & 36 & 36.4 & \\
\hline Total & & 99 & 100 & \\
\hline
\end{tabular}

Peer influence on the respondents' alcohol intake and alcohol effects on social life, family obligation and finances

A total of $98(99.0 \%$; $\mathrm{p}<0.0001)$ teachers had friends who take in alcohol and that $86.9 \%$ take alcohol with their friends
(Table 2). Approximately, 91.9\%, 97.0\% and 93.9\% agreed alcohol intake affects one's social life, family obligations and finances negatively (Table 2).

Table 2. Peer influence on the respondents' alcohol consumption and alcohol effects on social life, family obligation and finances.

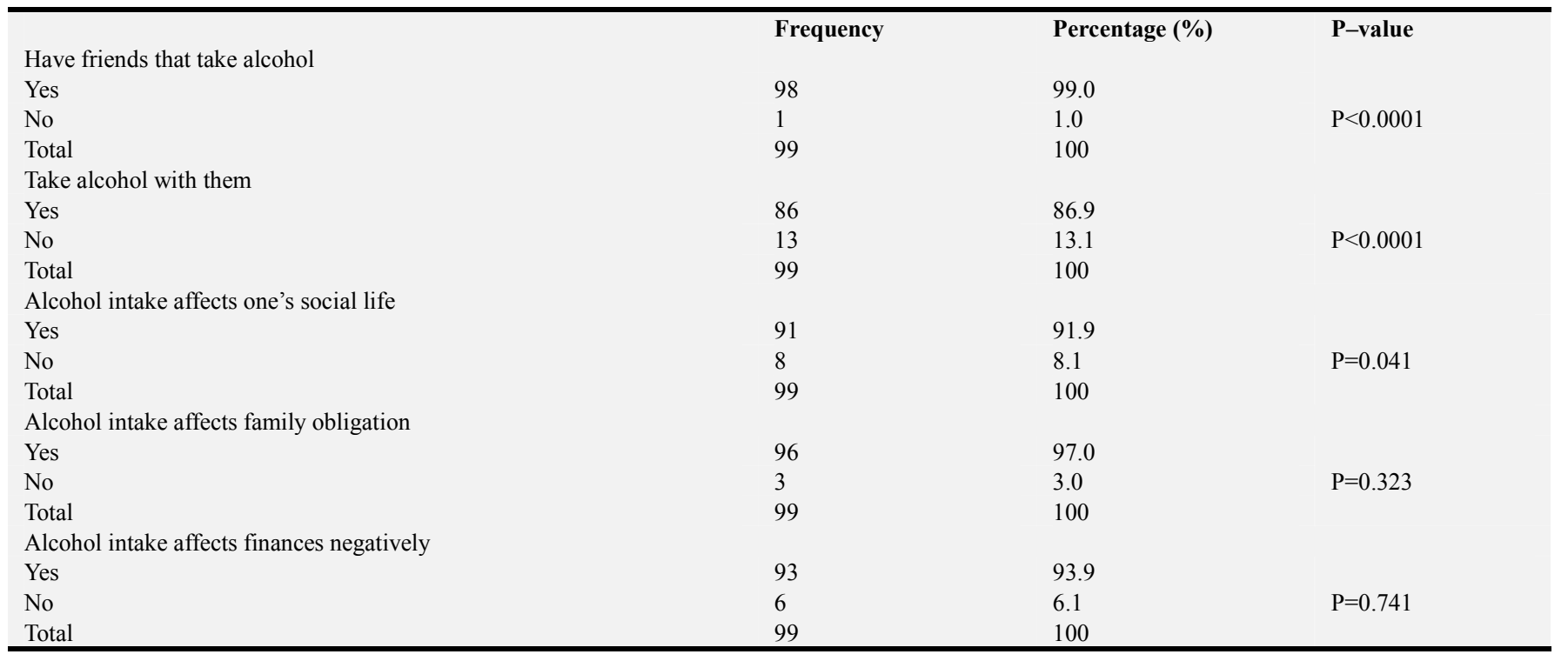

\section{Respondents' alcohol intake}

Majority $86(86.9 \%)$ of the respondents identified alcohol intake to be a problem among teachers. The commonest reason why teachers take in alcohol was for socialisation 46 $(46.5 \%)$. Many $63(63.6 \%)$ of the teachers take in alcohol every day, and that $80(80.8 \%)$ have been taken alcohol for 
over one year now. Beer was the alcoholic beverage commonly consumed by teachers (45.4\%) (Table 3 ).

Table 3. The pattern of alcohol intake by respondents.

\begin{tabular}{|c|c|c|}
\hline & Frequency & Percentage (\%) \\
\hline \multicolumn{3}{|c|}{ Alcohol intake a problem among teachers } \\
\hline Yes & 86 & 86.9 \\
\hline No & 13 & 13.1 \\
\hline Total & 99 & 100 \\
\hline \multicolumn{3}{|l|}{ Take alcohol } \\
\hline Yes & 99 & 100 \\
\hline No & 0 & 0.0 \\
\hline Total & 99 & 100 \\
\hline \multicolumn{3}{|c|}{ Why do you take alcohol } \\
\hline For relaxation & 31 & 31.1 \\
\hline For socialization & 47 & 47.5 \\
\hline To forget of problems & 21 & 21.2 \\
\hline Total & 99 & 100 \\
\hline \multicolumn{3}{|c|}{ Take alcohol every day or occasional } \\
\hline Every day & 63 & 63.6 \\
\hline Occasionally & 36 & 36.4 \\
\hline Total & 99 & 100 \\
\hline \multicolumn{3}{|c|}{ How long have you been taking alcohol } \\
\hline 6 months & 7 & 7.1 \\
\hline 1 year & 12 & 12.1 \\
\hline Over 1 year & 80 & 80.8 \\
\hline Total & 99 & 100 \\
\hline \multicolumn{3}{|c|}{ What alcohol beverage do you take } \\
\hline Beer & 45 & 45.4 \\
\hline Guinness & 21 & 21.2 \\
\hline Pito & 13 & 13.1 \\
\hline Spirits & 6 & 6.1 \\
\hline Not specific & 8 & 8.1 \\
\hline Others & 6 & 6.1 \\
\hline Total & 99 & 100 \\
\hline
\end{tabular}

Effects of alcohol intake on the respondents work

Many of the teachers take in alcohol before going to teach (58.6\% op=0.0227). Approximately, 43.4\% take alcohol after work, while $23.2 \%$ drink anytime during the day (figure 1 ). A total of $33(33.3 \%)$ teachers spent more than one hour at a drinking spot (Figure 2). Many 64 (64.6\%) of the respondents agreed that some teachers take in alcohol and become intoxicated.

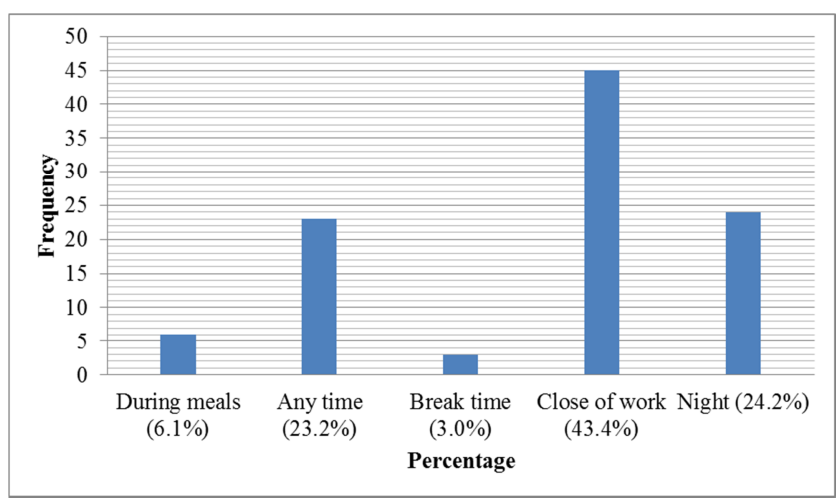

Figure 1. The time of day teachers drink alcohol in the BND.

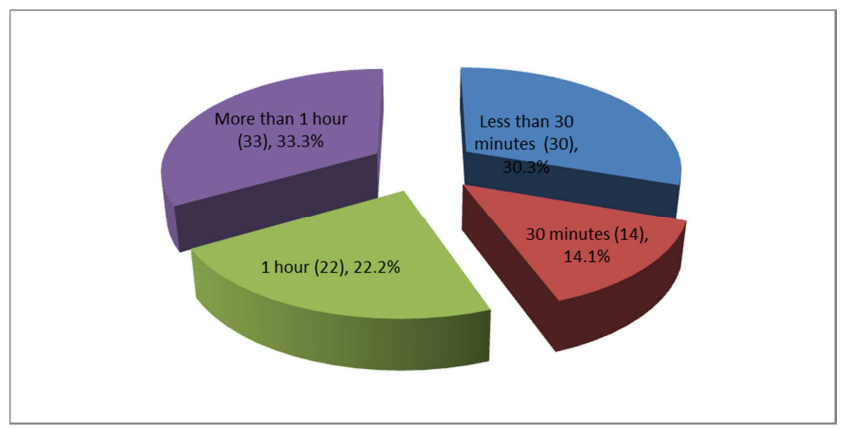

Figure 2. The time spent by teachers in the BND at a drinking spot.

Majority experienced hangover while in the classroom $(73.7 \% \mathrm{p}<0.0001)$. Also, the great majority $(88.9 \%$ $\mathrm{p}<0.0001)$ absent themselves at time from school due to previous day alcohol intake (Table 4). Approximately, 84.9\% of the respondents agreed that teacher who take in alcohol, miss lessons Also, many $74.7 \%$ of the respondent agreed that some teachers are not able to finish the syllabus due to alcohol intake (Table 4).

Table 4. Effects of alcohol intake on the work performance of teachers in the BND.

\begin{tabular}{|c|c|c|c|c|}
\hline Variable & & Frequency & Percentage (\%) & P-value \\
\hline \multirow{3}{*}{ Take in alcohol and go to school to teach? } & Yes & 58 & 58.6 & \multirow{3}{*}{$\mathrm{P}=.0227$} \\
\hline & No & 9 & 9.1 & \\
\hline & Sometimes & 32 & 32.3 & \\
\hline Total & & 99 & 100 & \multirow{5}{*}{$\mathrm{P}<0.000$} \\
\hline \multirow{3}{*}{$\begin{array}{l}\text { Take in alcohol and experience hangover whiles at } \\
\text { work? }\end{array}$} & Yes & 73 & 73.7 & \\
\hline & No & 25 & 25.3 & \\
\hline & Sometimes & 1 & 1.0 & \\
\hline \multirow[t]{2}{*}{ Total } & & 99 & 100 & \\
\hline & Yes & 88 & 88.9 & \multirow{3}{*}{$\mathrm{P}<0.000$} \\
\hline \multirow[t]{2}{*}{ Absent from school due to alcohol intake? } & No & 11 & 11.1 & \\
\hline & Sometimes & 1 & 1.0 & \\
\hline \multirow[t]{2}{*}{ Total } & & 99 & 100 & \multirow{4}{*}{$\mathrm{P}<0.000$} \\
\hline & Yes & 84 & 84.9 & \\
\hline \multirow[t]{2}{*}{ Miss lessons in school due to alcohol intake? } & No & 14 & 14.1 & \\
\hline & Sometimes & 1 & 1.0 & \\
\hline Total & & 99 & 100 & \\
\hline Not able to finish syllabus due to alcohol intake? & Yes & 74 & 74.7 & $\mathrm{P}<0.0001$ \\
\hline
\end{tabular}




\begin{tabular}{|c|c|c|c|c|}
\hline Variable & & Frequency & Percentage (\%) & P-value \\
\hline \multirow{3}{*}{ Total } & No & 25 & 25.3 & \\
\hline & & 99 & 100 & \\
\hline & Any time & 21 & 21.2 & \\
\hline \multirow{3}{*}{ Time of the day you consume alcohol? } & Break time & 9 & 9.1 & \\
\hline & Close of work & 45 & 45.5 & \\
\hline & Night & 24 & 24.2 & \\
\hline \multirow[t]{2}{*}{ Total } & & & 100 & \\
\hline & Less than 30 minutes & 30 & 30.3 & \\
\hline \multirow{3}{*}{ What amount of time do you spend on taking alcohol? } & 30 minutes & 14 & 14.1 & \\
\hline & 1 hour & 22 & 22.2 & \\
\hline & More than 1 hour & 33 & 33.3 & \\
\hline \multirow[t]{2}{*}{ Total } & & 99 & 100 & \\
\hline & Yes & 15 & 15.2 & \\
\hline \multirow[t]{2}{*}{ Consume alcohol and become intoxicated? } & No & 35 & 35.4 & \\
\hline & Sometimes & 49 & 49.4 & \\
\hline Total & & 99 & 100 & \\
\hline
\end{tabular}

\section{Discussion}

\section{Socio-demographic characteristics of respondents}

The current study found that the great majority $(84.9 \%)$ of the teachers in active service within the BND who drink alcohol were younger than 38 years old with a mean age of $33.5 \pm 6.1$ years. The age characteristics of this study in the BND are consistent with reports of other studies among different professional groups across Africa [7-9]. For instance, Ovuga et al., (2006) [7], conducted a study on alcohol consumption among the police force in Kampala, Uganda and found the habit to be common among young policemen. Again, a study conducted in Nigeria by Babalola et al., (2017) [9] found hazardous alcohol consumption pattern among younger than 40 years of age. Alcohol was found to be much common among male teachers compared to their female counterparts $(\mathrm{p}<0.0001)$ with a male to female ratio of $3: 1$. The gender characteristics of alcohol consumption as reported in this current study is in line with reports from the GDHS, (2008) [10] and Yawson et al., (2015), [11] which suggested that, in Ghana more men consumed alcohol than women. Similar observations were made by Molnuddin et al., (2016) [12] in their study on alcohol consumption and gender characteristics in India.

Alcohol consumption was found to be common among married teachers $(\mathrm{P}<0.0001)$. This supports previous studies in Ghana on marital status and alcohol consumption by Adusi-Poku, et al., (2013), [13] and Tampah-Naah, et al (2015) [14]. For instance, Tampah-Naah, et al., (2015) [11] in a study titled "Consumption and drinking frequency of alcoholic beverage among women in Ghana: a crosssectional study" found positive statistical significant association $(\mathrm{p}<0.0001)$ between marital status and alcohol consumption patterns. Majority of the teachers who consumed alcohol were Builsa by tribe. This is because the study was conducted in the Bulsa land. This is however in line with reports of a study conducted by Friends of the Future, among five selected districts in the Upper East region which ranked the Builsa youth second in alcohol consumption with Navrongo youth in the Kassena Nankana District taking the first position (Ghana News Agency, 2010) [15]. Furthermore, the increased alcohol consumption pattern as found in this current study supports reports globally [4, 16]. For instance, Lim et al., reported in their study that alcohol consumption moved from being the eighth highest ranked risk factor in1990 to the fifth highest ranked risk factor in 2010 [4].

The study found that $87.9 \%$ of the respondents were Christians, compared to the other religions combined, with significant positive statistical association $(\mathrm{p}<0.0001)$. This finding is in accordance with previous studies in Ghana by Adusi-Poku et al., (2013) [13] and Lamptey, (2005) [17] which reported higher alcohol consumption among Christians compared to their Muslims counterparts. For instance, Lamptey, (2005) [17] reported 82.8\% alcohol consumption among Christians compared to $11.5 \%$ among Muslims. Similar findings were reported in India in a study by Gupta et al., 2003 [18]. Regarding the schools that the respondents were teaching, the study there was a fair distribution of them across with $31.3 \%, 32.3 \%$ and $36.4 \%$ teaching in primary, junior high and senior high schools respectively in the district. However, the study found high educational level to be associated with increased alcohol consumption. For instance approximately $66.7 \%$ of the respondents who drink alcohol were university graduates $(<0.0001)$. Again the study found that $83.8 \% \quad(\mathrm{p}<0.0001)$, of the respondents were professionally trained teachers. This is in contrast to previous studies in Ghana and other parts of the world [12, 14, 18, 19], which reported high prevalence of alcohol consumption among persons with no or low education level.

Respondents in this current study agreed that alcohol consumption is a problem among teachers in Builsa North district $(p<0.0227)$ and this have negative impact on their work performance. The study established that hangovers while at work were a common feature among teachers who drink excess alcohol $(\mathrm{p}<0.0001)$ and potentially a low output of the individual while at work. This supports the findings of a study by Ames et al., (1997) [20] more than 2 decades ago which reported that Workers who had hangovers at work 
were significantly more likely to report that they had felt sick at work, had trouble getting their job done and fallen asleep on the job [20]. Similarly, Rukundo et al., (2013) [21] also reported in their study that alcohol consumption by teacher leads to poor decision making in assessing students, poor organization, planning and delivery of lessons and poor learning environment [21].

This study found that teachers who consumed alcohol were more likely to absent themselves from school $(p<0.0001)$ and the resultant effect will be poor academic performance by the students either at the end year examination or terminal examination. This finding is in line with a previous study in southern Ghana by Coleman et al., (2002) [20] which found that teachers who engage in excessive alcohol drinking may absent themselves from school because of hangovers and reduced energy due to dehydration and malnutrition [20]. Furthermore, $84.9 \%(p<0.0001)$ of the respondents in the study did indicate that teachers who miss lessons in school were those who drink alcohol. These findings of the current study affirmed findings of a previous study conducted by Rukundo et al., (2013) in Uganda [20].

Secondly, the study reveals that majority $(74.7 \%, \mathrm{p}<0.0001)$ of the teachers who consumed alcohol most often are not able to finish the syllabus. The study also found that teachers either drink during working time or spent so much time at a drinking spot. For instance, $21.2 \%$ of the respondents consume alcohol at any time during the day, while $55.5 \%$ spent one or more hours at a drinking spot. These potentially suggest a decrease pupil to teacher contact hours, for they are not able to continue with the work of the day, and this impact negatively on the child academic performance/achievements. Previous studies in Africa on the amount of time spent on alcohol consumption and the effect on work output and family like found that most drinking requires time (often spent with drinking colleagues) and this competes with the quality time required for any other routine work and social life including the care for families [9, 21-23]. For instance, a very recent study by Babalola, et al., (2017) on Alcohol Use among Secondary School Teachers in Southwestern Nigeria, reported that teachers who drink heavy alcohol had psychological distress and hence increased risk of alcohol related work place injuries and a reduced productivity [9]. Similarly, Booth et al., (2002) stated that the mere consumption of alcoholic beverage by any person may not predispose them to health or social consequences. It is rather the quantity of alcoholic beverage consumed and the drinking frequency that, importantly, can predict the likely health effects or other socially related consequences they encounter [23].

\section{Conclusion}

The study found that alcohol intake is a big problem especially among young teachers in the district. The act affects the routine work performance of the teachers with a resultant negative impact on the pupils academic achievements and progression.

\section{Recommendations}

1. The by-laws of the Ghana education service and the ministry of education regarding the ethics of the profession should be enforced to the later.

2. The supervisory role of the district directors of education and the heads of schools should intensify and conducted regularly, and should be given the powers to query teachers found guilty of an offense.

3. Parents and guardians of the pupils should regularly walk into the schools to monitor the present of their wards and their teachers. Teachers who are known to be absenting themselves from school and are often not able to finish the syllabus should have their salary stopped to serve as warning.

4. The Ghana Education Service should have a policy as part of their in service training or refresher courses to organise workshops on alcohol and substance abuse where the effects of these are highlighted clearly for the participants to see the effects alcohol intake and substance abuse have on their lives and work.

\section{Conflict of Interest}

There is no conflict of interest.

\section{Availability of Data}

The data used to prepare this manuscript shall be made available upon request by the editor-in-chief.

\section{Author's Contributions}

AYW and DEM conceptualized the manuscript. AYW collected and analysed data. AYW and DEM wrote the manuscript, read through the final manuscript approve it for publication.

\section{Ethical Consideration/Informed Consent}

This manuscript is an extract from a dissertation submitted to the graduate school of the University for Development Studies (UDS) for the award of a Master of Science degree in community health and development. The university officially wrote to the district director of the Ghana Education Service seeking permission to allow the researcher to carry out the study and the opportunity was granted. The consent participants were sought by the researcher. The objectives of the study were explained to the participants. Confidentially of respondents was assured. Participants were given the option to withdraw at any time in the course of given out information.

\section{Acknowledgements}

We thank the Director of the Ghana Education Service for Builsa North district and his staff, most especially the Coordinator for the Girl Child Education; Madam Lydia 
Azangtilow. We also express our gratitude to all those who have contributed in one way or the other to make this research a success.

\section{References}

[1] World Health Organisation. Global Status Report on Alcohol and Health. Geneva: World Health Organisation. (2014).

[2] J. Rehm, C. Mathers, S. Popova, M. Thavorncharoensap, Y. Teerawattananon, J. Patra. Global burden of disease and injury and economic cost attributableto alcohol use and alcohol use disorders. Lancet. 2009; 373: 2223-33. 2.

[3] Humeniuk RE, Henry-Edwards S, Ali RL, Poznyak V, Monteiro M. The ASSISTlinked brief intervention for hazardous and harmful substance use: manual foruse in primary care. Geneva: World Health Organization (WHO), Department of Mental Health and Substance Abuse; 2010.

[4] S. Lim, T. Vos, A. Flaxman, G. Danaei, K. Shibuya, et al. A comparative risk assessment of the burden of disease and injury attributable to 67 risk factors and risk factor clusters in 21 regions, 1990-2010: a systematic analysis for the Global Burden of Disease Study 2010. Lancet. 2012; 380: 2224-60.

[5] T. I. Myadze, A. Rwomire. Alcoholism in Africa during the Late Twentieth Century: A Socio-Cultural Perspective. International Journal of Business and Social Science, 2014, 5 (2).

[6] Ghana Statistical Service. District Analytical Report: Builsa North District (GSS 2014).

[7] E. Ovuga, C. Madrama. Burden of alcohol use in the Uganda Police in Kampala District. Afr Health Sci. 2006; 6: 14-20.

[8] L. Brown. Health Survey for England 2015: adult alcohol consumption. Leeds: NHS Digital; 2016.

[9] E. Babalola, M. Ighoroje, S. Awhangansi, O. Ayilara. Psychosocial Correlates of Hazardous Alcohol Use among Secondary School Teachers in Southwestern Nigeria. International Journal of Clinical Psychiatry. 2017; 5: 16-23 doi: $10.5923 /$ j.ijcp.20170501.03.

[10] Ghana: Ghana Statistical Service (GSS). Ghana demographic and health survey Health Service, and ICF Macro. 2008. Accra, Ghana.

[11] AE. Yawson, J. Welbeck, BJ. Agyenim, G. Mensah, N.
Minicuci, N. Naidoo., et al. Sociodemographic and Socioeconomic Correlates of Alcohol Use among Older Adults in Ghana. J Alcohol Drug Depend 2015; 3: 202. doi: 10.4172/2329-6488.1000202.

[12] A. Moinuddin, A. Goel, S. Saini, A. Bajpai, R. Misra. Alcohol Consumption and Gender: A Critical Review. J Psychol Psychother. 2016; 6: 267. doi: 10.4172/2161-0487.1000267.

[13] Y. Adusi-Poku, AA. Bonney, GD. Antwi. Where, When and What Type of Alcohol do Pregnant Women Drink? Ghana Med J. 2013; 47: 35-39.

[14] AM. Tampah-Naah, ST Amoah. Consumption and Drinking Frequency of Alcoholic Beverage Among Women in Ghana: A cross-sectional study. BMC Public Health; 201515: 317 https://doi.org/10.1186/s12889-015-1651-3.

[15] Ghana News Agency. Coalition bemoans spate of alcohol consumption in Upper East Region. 2013, May 3.

[16] A. Abbey. Alcohol-related sexual assault. A common problem among college students. J Stud Alcohol Suppl. 2002; 14: 11828.

[17] JJ. Lamptey. Socio-demographic Characteristics of Substance Abusers Admitted to a Private Specialist Clinic. Ghana Med J. 2005; 39: 2-7.

[18] AU. Emilia, E. Alfred, A. Georgetta. Factors Associated with Alcohol Consumption: A Survey of Women Childbearing at a National Referral Hospital in Accra, Ghana. African Journal of Reproductive Health, 2014; 18 (2).

[19] European Alcohol Policy Alliance. National Conference on Alcohol Policy. Vol 3, 2010.

[20] GM. Ames, JW. Grube, RS. Moore. The relationship of drinking and hangovers to workplace problems: an empirical study. J Stud Alcohol. 1997; 58: 37-47.

[21] A. Rukundo, J. Magambo. Professional Impotence: Impact of alcohol abuse on secondary schools teachers in Uganda. International Journal of Alcohol and Drug Research, 2013; 2: 69-74.

[22] L. Coleman, S. Cater. What do we know about young people's use of alcohol? Education and Health. 2003; 21: 50-5.

[23] BM. Booth, W. Feng. The impact of drinking and drinking consequences onshort-term employment outcomes in at-risk drinkers in six southern states. J Behav Health Serv Res. 2002; 29: 157-166. 